\title{
A Suitable Shape of the Suction Head for a Cleaning Process in a Factory Developed by Computational Fluid Dynamics
}

\author{
Jatuporn Thongsri *(D), Worapol Tangsopa (D) and Jirawat Khongsin \\ Computer Simulation in Engineering Research Group, College of Advanced Manufacturing Innovation, \\ King Mongkut's Institute of Technology Ladkrabang, Bangkok 10520, Thailand; worapol.plz@gmail.com (W.T.); \\ jirawat.khongsin@gmail.com (J.K.) \\ * Correspondence: jatuporn.th@kmitl.ac.th
}

Citation: Thongsri, J.; Tangsopa, W.; Khongsin, J. A Suitable Shape of the Suction Head for a Cleaning Process in a Factory Developed by Computational Fluid Dynamics. Processes 2021, 9, 1902. https:// doi.org/10.3390/pr9111902

Academic Editors: Weizhong Dai and Krzysztof Rogowski

Received: 3 September 2021

Accepted: 14 October 2021

Published: 25 October 2021

Publisher's Note: MDPI stays neutral with regard to jurisdictional claims in published maps and institutional affiliations.

Copyright: (c) 2021 by the authors. Licensee MDPI, Basel, Switzerland. This article is an open access article distributed under the terms and conditions of the Creative Commons Attribution (CC BY) license (https:// creativecommons.org/licenses/by/ $4.0 /)$.

\begin{abstract}
The previous shape of the suction head ( $\mathrm{SH}$ ) employed in a cleaning process in a factory had a low performance, removed fewer particles, and generated an annoying noise. Therefore, new shapes of $\mathrm{SH}$ have been proposed to solve the issues and the cleaning performance was investigated by the Shear Stress Transport (SST) $k$ - $\omega$ turbulence, Discrete Phase (DP), Large Eddy Simulation (LES), and Ffowcs Williams and Hawkings (FW-H) models in a transient state of computational fluid dynamics (CFD). The SST $k-\omega$ and DP models were applied to determine the airflow, suspension velocity, cleaning region, and particle trace. In addition, the LES and FW-H models were used to evaluate the noise, sound pressure level, and frequency generated from the proposed shapes. All simulation results were validated with the air velocity and noise measurements and were analyzed to find a suitable shape. The simulation and experimental results revealed that the shapes of the $\mathrm{SH}$ affected the cleaning performance and noise generation. The higher the air velocity, the higher the noise generation. The suitable shape delivered a $4.37 \%$ better particle removing performance and $11.1 \mathrm{~dB}$ less noise generation than the previous shape. The outcomes of this research are the suitable shape of the SH and the research methodology which enabled the application of both CFD and experiments to solve the issue to help enhance the efficiency of the cleaning process in an actual factory.
\end{abstract}

Keywords: airflow; cleaning process; computational fluid dynamics (CFD); discrete phase; Ffowcs Williams and Hawkings; large eddy simulation; shear stress transport $k-\omega$; sound noise; suction head

\section{Introduction}

The manufacturing of electric devices and components is one of the leading industries in Thailand. Major export products are hard disk drives, integrated circuits, print circuit boards, semiconductors, and electronic parts. The manufacturing of these products requires a cleaning process to control dust, dirt, skin, and microorganism particles to at least ISO6 of US FED STD 209E cleanroom [1,2], since the attachment of the mentioned particles can cause particle contamination issues in the electronic circuitry causing the products to malfunction. Particle contamination can occur for two reasons: the manufacturing process and the operators' activity; therefore, to avoid the issues, the products must be manufactured in a clean room with a well-designed ventilation system and cleaning process.

Suppose the production line has issues with contamination that exceed the standard. In that case, maintenance engineers will assess the situation to determine whether a solution is consistent with global exhaust ventilation or local exhaust ventilation. First, the key is to change the airflow, air change rate, the layout of the machine installation, etc., of the cleanroom [2-4] and wear the proper uniform of operators [5]. For the latter, the solution can be obtained by changing the conditions of the air circulation system, especially in the machines [6], installing the fan filter unit [7], modifying the hood's shape [8,9], and adding the cleaning process [10-12]. In brief, the global and local exhaust ventilations consist of three main components: suction head or hood, duct, and vacuum pump. The 
suction head (SH) is an essential accessory that assists the ventilation system. Obviously, its shape affects the cleaning performance $[8,9,12]$, so the SH's shape is one of the essential elements in the cleaning process of the factory. In the past, the design of the SH's shape was based on the Dalla Valle [13], Garrison [14], Fletcher [15], Tyaglo and Shepelev [16], and Posokhin [17] equations to predict centerline velocity, a significant factor for investigating particle removal capability.

However, all the equations mentioned above were proven and derived from the $\mathrm{SH}^{\prime} \mathrm{s}$ cross-section in 2D, so their practical application is limited. For example, the Dalla Valle and Garrison equations are valid only for an $\mathrm{SH}$ with a circular cross-section. At the same time, the Fletcher and Tyaglo and Shepelev equations are applicable only for rectangular cross-sections. The Dalla Valle and Fletcher equations work best only when the SH has a splay angle of less than 30 degrees. The greater the splay angle, the higher the error in the prediction of centerline velocity. The mentioned equations are still used in fundamental study and simple tasks $[18,19]$. In the leading industries, the mentioned equations are insufficient for use in the SH's design, as the factory's operating and environmental conditions are more complex. For example, in a factory with large production lines where the $\mathrm{SH}$ is required to clean the local exhaust ventilation, a single $\mathrm{SH}$ can make a small amount of sound noise. Still, together they can create an annoying noise, which can cause noise pollution. Therefore, a suitable $\mathrm{SH}$ is a suction device that removes many particles and generates low noise. Computational fluid dynamics (CFD) were recently employed to verify the removal performance of bowl-type and straight-type SHs in practice at an actual factory. We found that the bowl type was more effective in removing the particles in space and above the work area than the straight type, and the removing distance of $5 \mathrm{~mm}$ above the work area gave the best performance [12]. After usage in the actual factory, operators complained that the bowl-type $\mathrm{SH}$ caused a noise pollution issue; therefore, an improvement to find a suitable shape was urgently needed.

Research has shown that the Shear Stress Transport (SST) $k-\omega$ turbulence and Discrete Phase (DP) models in CFD have been used for particle tracking to address the issues of over-contamination in the factory $[6,12,20]$. Therefore, both models can be used to investigate the particulate removing efficiency. Furthermore, the Large Eddies Simulation (LES), one of the turbulence models, and Ffowcs Williams and Hawkings (FW-H), one of the acoustic models in CFD, were used to investigate the sound pressure level (SPL) to address the noise pollution issue [21-24]. Therefore, all mentioned models in CFD have the potential to solve our problem.

This article aims to extend the research in [12] by proposing five new SH shapes in addition to the two shapes in [12], a total of seven shapes, to find a suitable shape with a higher efficacy based on CFD. The study was divided into two parts: simulation and experiment. In the simulation, the airflow, particle trace, suspension velocity, cleaning region, and noise generated by various SH shapes were determined using the SST $k-\omega$ and DP models to assess the particle removing capability. In addition, the SPL and frequency were calculated using the LES and FW-H models to evaluate the noise generation. In the experiments, all $\mathrm{SH}$ shapes were created by 3D printing and were employed to mimic the cleaning process. A hot-wire anemometer and a Decibel $\mathrm{X}$ application in a mobile phone were used to measure the variables mentioned above for comparison to verify the simulation results. Finally, all results were analyzed to find the suitable shape of SH. The importance of this research is in the use of a simulation with four mathematical models in CFD and simple experiments to solve the issues. We report the research methodology step-by-step, leading to the suitable SH shape, implemented in the actual factory.

\section{Theoretical Background}

The SST $k-\omega$, DP, LES, and FW-H are mathematical models in ANSYS Fluent software, a highly accepted CFD software used to solve problems in the manufacturing process [20,24-27]. The governing equations are mentioned below. 


\subsection{SST $k-\omega$}

The airflow can be calculated by solving Reynolds-Averaged Navier-Stokes (RANS) equations consisting of conservation and turbulence equations. The conservation equations include conservations of mass (1) and momentum (2). For an incompressible flow and Newtonian fluid in a transient state, both can be expressed by:

$$
\begin{gathered}
\frac{\partial \rho}{\partial t}+\nabla \cdot(\rho \vec{u})=0 \\
\frac{\partial(\rho \vec{u})}{\partial t}+\nabla \cdot(\rho \vec{u} \otimes \vec{u})=-\nabla p+\nabla \cdot \tau+\vec{S}_{M}
\end{gathered}
$$

where $\vec{u}$ is the mean velocity, $\rho$ is the fluid density, $p$ is the pressure, $\vec{S}_{M}$ is the momentum source term, and $\tau$ is the stress tensor related to the strain rate as follows:

$$
\tau=\mu\left(\nabla \vec{u}+(\nabla \vec{u})^{T}-\frac{2}{3} \delta \nabla \cdot \vec{u}\right)
$$

From the calculation based on the actual conditions at the factory, we found that the Reynolds numbers $(R e)$ were between $5 \times 10^{3}-2 \times 10^{5}$, which matched the SST $k-\omega$ turbulence model. The SST $k-\omega$ equations can be written as $[6-8,12,25,27]$ :

$$
\begin{gathered}
\frac{\partial}{\partial x_{j}}\left(\rho U_{j} k\right)=\frac{\partial}{\partial x_{j}}\left(\left(\mu+\frac{\mu_{t}}{\sigma k_{3}}\right) \frac{\partial k}{\partial x_{j}}\right)+P_{k}-0.09 p k \omega \\
\frac{\partial}{\partial x_{j}}\left(\rho U_{j} \omega\right)=\frac{\partial}{\partial x_{j}}\left(\left(\mu+\frac{\mu_{t}}{\sigma \omega_{3}}\right) \frac{\partial \omega}{\partial x_{j}}\right)+1.71\left(1-F_{1}\right) \frac{\rho}{\omega} \frac{\partial k}{\partial x_{j}} \frac{\partial \omega}{\partial x_{j}}+\alpha_{3} \frac{\omega}{k} P_{k}-\beta_{3} \rho \omega^{2}
\end{gathered}
$$

where $\mu$ is the molecular dynamics viscosity, $\mu_{t}$ is the eddy viscosity, and $P_{k}$ is the shear production of turbulence. $\omega$ is the specific dissipation rate, $k$ is the turbulent kinetic energy, $F_{1}$ is the blending function, and $\alpha, \beta$, and $\sigma$ are the specific coefficients for the SST $k-\omega$ turbulence model.

The airflow calculated by solving Equations (1)-(4) was used as the initial condition for setting to determine further the pressure, air velocity, particle trace, cleaning region, suspension velocity, and noise. When the cleaning process is in operation, the air velocity around the $\mathrm{SH}$ is different. Suspension velocity $\left(v_{S}\right)$ is the most negligible velocity at which particles are raised to float up to the $\mathrm{SH}$, i.e., when the air velocity at any position is less than $v_{s}$, the particles would not be sucked into the SH. On the other hand, when the air velocity is higher than the suspension velocity, the particles would be sucked into the $\mathrm{SH}$. Assuming that the particles are solid spheres with a constant density and tiny size, and do not change the air direction, the suspension velocity is given in [12]. The $v_{s}$ is used as a threshold for performance quantification.

$$
v_{s}=5.45 \sqrt{\frac{d_{p}\left(\rho_{p}-\rho\right)}{\rho}}
$$

where $\rho_{p}$ is the particle density and $d_{p}$ is the particle diameter.

\section{2. $L E S$}

This model consumes more computational time and resources than the SST $k-\omega$ model but provides more accurate noise generation results and reduces the turbulence model error rather than directly calculating it from the SST $k-\omega[23,25]$. The LES is suitable for the fluid with $R e$ in the range of $10^{4}-10^{5}$, consistent with this research. In ANSYS Fluent 
software, the LES is based on Filtered Navier-Stokes equations; that is, some parameters in the conservation equation can be rewritten as [23-25]:

$$
\begin{gathered}
\frac{\partial}{\partial x_{i}}\left(\bar{u}_{i}\right)=0 \\
\frac{\partial}{\partial t}\left(\rho \bar{u}_{i}\right)+\frac{\partial}{\partial x_{j}}\left(\rho \bar{u}_{i} \bar{u}_{j}\right)=-\frac{\partial \bar{p}}{\partial x_{i}}+2 \frac{\partial}{\partial x_{j}}\left(\mu \bar{S}_{i j}\right)-\frac{\partial}{\partial x_{j}}\left(\tau_{i j}\right) \\
\bar{S}_{i j}=\frac{1}{2}\left(\frac{\partial \bar{u}_{j}}{\partial x_{i}}+\frac{\partial \bar{u}_{i}}{\partial x_{j}}\right) \\
\tau_{i j}=\rho\left(\overline{u_{i} u_{j}}-\overline{u_{j} u_{i}}\right)
\end{gathered}
$$

The overline symbol means the filtering operation. The Equations (6)-(9) are improved by the subgrid-scale and Smagorinsky models, which change some valuables and constants for more accurate results [23-25]. The airflow obtained from the LES was used as the initial setting for further noise calculation.

\section{3. $D P M$}

The mentioned airflow calculated from Equations (1)-(4) was transferred to the DPM as the initial condition for particle trace simulation. In the DPM, the particle force balance equation, an equation for calculating the particle trace, is given by $[6,26]$ :

$$
\frac{d u_{p}}{d t}=F_{D}\left(u_{f}-u_{p}\right)+\frac{g\left(\rho_{p}-\rho_{f}\right)}{\rho_{p}}+F_{s}
$$

where $F_{D}$ is the drag force, $F_{s}$ is the external force, and $g$ is the gravity. The subscripts $f$ and $p$ refer to the fluid and particle, respectively.

Since the dirt particles are tiny, their trajectories do not affect the direction of airflow. Particles can change direction only under the influence of airflow or when they collide with other particles. The external force in Equation (10) is considered only as Saffman's lift force because other forces, such as virtual mass and pressure gradient forces, are deemed to be less effective if it is assumed that tiny particles in a shear field experience a lift force perpendicular to the flow direction and are not spinning. The shear lift originates the inertia effects in the viscous flow around the particles. The Saffman's lift force is [20]:

$$
\vec{F}=\frac{2 K \rho_{f} v^{1 / 2} d_{i j}\left(\vec{u}_{f}-\vec{u}_{p}\right)}{\rho_{p} d_{p}\left(d_{l k} d_{k l}\right)^{1 / 4}}
$$

where $K$ is $2.594, v$ is the fluid viscosity, and $d_{i j}, d_{j k}$, and $d_{j k}$ are the deformation tensors.

When Equations (1)-(11) are solved, the airflow, air velocity, cleaning region, suspension velocity, and particle trace can be determined to assess the particle removing performance.

\section{4. $F W-H$}

In the $\mathrm{FW}-\mathrm{H}$, the inhomogeneous wave equation is derived from the continuity equation of the Navier-Stokes equation and can be expressed as [24]:

$$
\begin{gathered}
\frac{1}{a_{0}^{2}} \frac{\partial^{2} p^{\prime}}{\partial t^{2}}-\nabla^{2} p^{\prime}=\frac{\partial^{2}}{\partial x_{i} \partial x_{j}}\left\{T_{i j} H(f)\right\}-\frac{\partial}{\partial x_{i}}\left\{\left[P_{i j} n_{j}+\rho u_{i}\left(u_{n}-v_{n}\right)\right] \delta(f)\right\} \\
+\frac{\partial}{\partial t}\left\{\left[\rho_{0} v_{n}+\rho\left(u_{n}-v_{n}\right)\right] \delta(f)\right\} \\
T_{i j}=\rho u_{i} u_{j}+P_{i j}-\alpha_{0}^{2}\left(\rho-\rho_{0}\right) \delta_{i j}
\end{gathered}
$$


where $u_{i}$ is the fluid velocity component in the $\mathrm{x}$-direction and $u_{n}$ is the fluid density normal to the surface. $v_{i}$ and $v_{n}$ are the surface velocity components in the x-direction and normal to the surface, respectively. $\delta(f)$ is the Dirac delta function. $H(f)$ is the Heaviside function. $p^{\prime}$ is the sound pressure at the far-field $\left(p^{\prime}-p_{0}\right) . f$ is a specific value to indicate the position. $\alpha_{0}$ is the far-field sound speed. $T_{i j}$ and $P_{i j}$ are the Lighthill and compressive stress tensors, respectively. The free-stream quantities are denoted by the subscript 0 .

For a Stokesian fluid, a type of fluid flow where advective inertial forces are small compared with viscous force, $P_{i j}$ is given by [25]:

$$
P_{i j}=p \delta_{i j}-\mu\left[\frac{\partial u_{i}}{\partial x_{j}}+\frac{\partial u_{j}}{\partial x_{i}}-\frac{2}{3} \frac{\partial u_{k}}{\partial x_{k}} \delta_{i j}\right]
$$

Pressure and related parameters computed with the LES described above were sent as the initial condition. After solving Equations (12)-(14), $p^{\prime}$ at the different positions in the transient state was calculated. The equivalent A-weighted SPL $\left(L_{A e q}\right)$, which represents the noise generated by the $\mathrm{SH}$, was calculated using the following equation [28]:

$$
L_{\text {Aeq }}=10 \log _{10}\left(\frac{1}{\Delta t} \int_{t_{i}}^{t_{f}}\left(\frac{p^{\prime}(t)}{p_{0}}\right) d t\right)
$$

where $p_{0}$ is the reference sound pressure of $20 \mu \mathrm{Pa}$ and $p(t)$ is the continuous sound pressure. $t_{i}$ and $t_{f}$ are the initial and end-times, respectively.

In the case of multiple frequencies or sound sources, the total of $L_{\text {Aeq }}$ is as follows [28]:

$$
\text { Total } L_{\text {Aeq }}=10 \log \left[\frac{1}{N} \sum_{i=1}^{N}\left(10^{\frac{L_{\text {Aeq }, i}}{10}}\right)\right]
$$

where $N$ is the number of the source.

\section{Methodology}

The research methodology revealed in Figure 1 consists of two parts: simulation and experiment. The proposed SHs were investigated for their cleaning performance in two usage situations: in space and $5 \mathrm{~mm}$ above the work area. The $5 \mathrm{~mm}$ is the optimal distance for cleaning mentioned in $[11,12]$. This section describes the detail step-by-step from the start until the suitable SH shape was obtained.

\subsection{A Suction Head}

The actual SH of the factory was a bowl type with a handle that could be adjusted direction for convenience in operation and had a splay angle of $30^{\circ}$ as shown in Figure $2 \mathrm{a}$. Therefore, this research proposed new models with angles of $15^{\circ}, 45^{\circ}, 60^{\circ}, 75^{\circ}$, and $90^{\circ}$, including the previous models with $0^{\circ}$ and $30^{\circ}$ in [12] as candidates for the suitable $\mathrm{SH}$ shape. Figure $2 \mathrm{~b}$ shows an example of a splay angle of $60^{\circ}$ as a fluid model created for simulation. In addition, the $\mathrm{SH}$ and duct were simplified to be connected without joints. A simplified model such as this helps avoid backflow. The backflow causes the calculation results to be incorrect and to diverge. The other $\mathrm{SH}$ shapes were precisely the same as in Figure $2 \mathrm{~b}$ but differed only in the splay angles. 


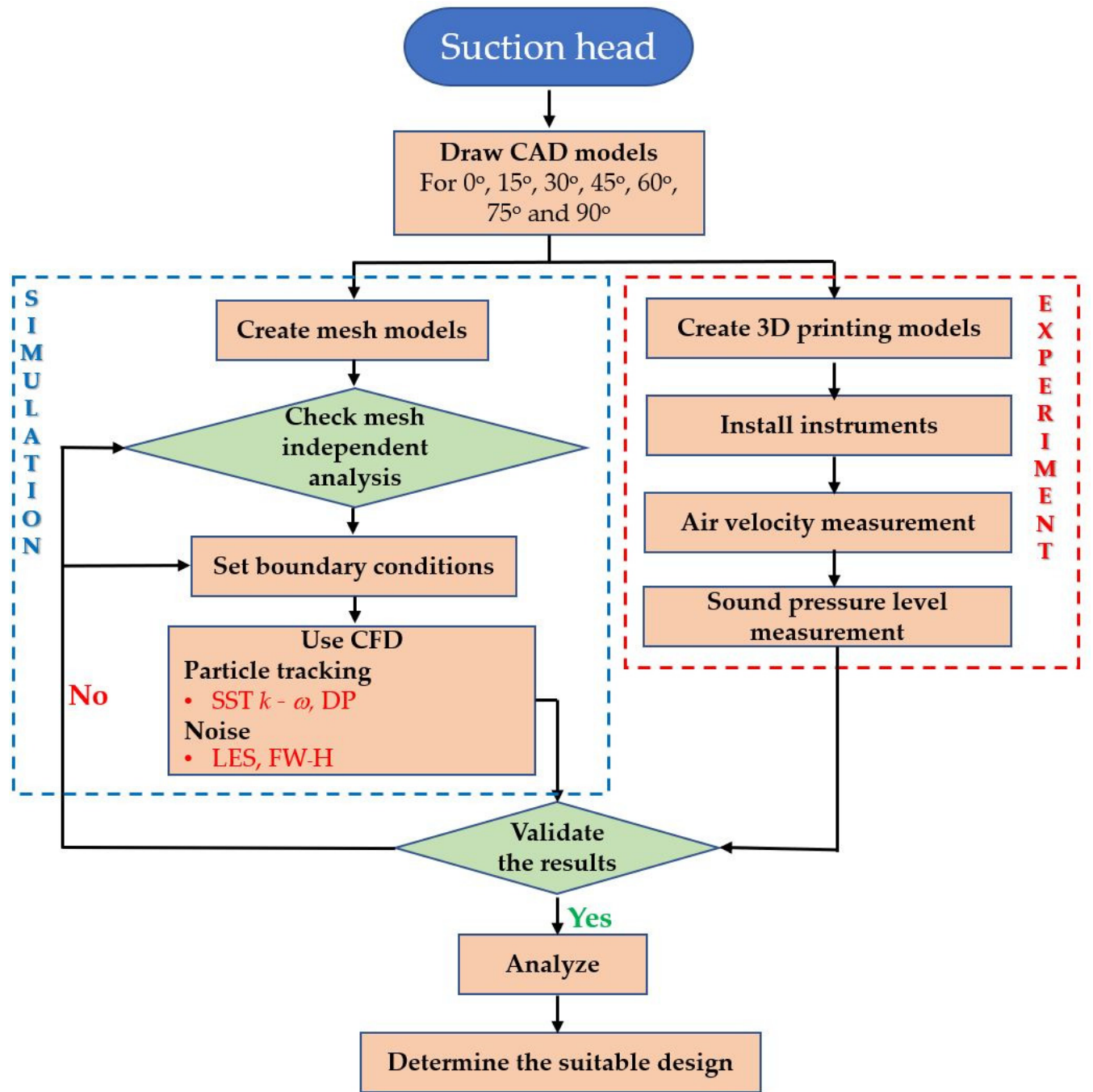

Figure 1. A flowchart of the research methodology.

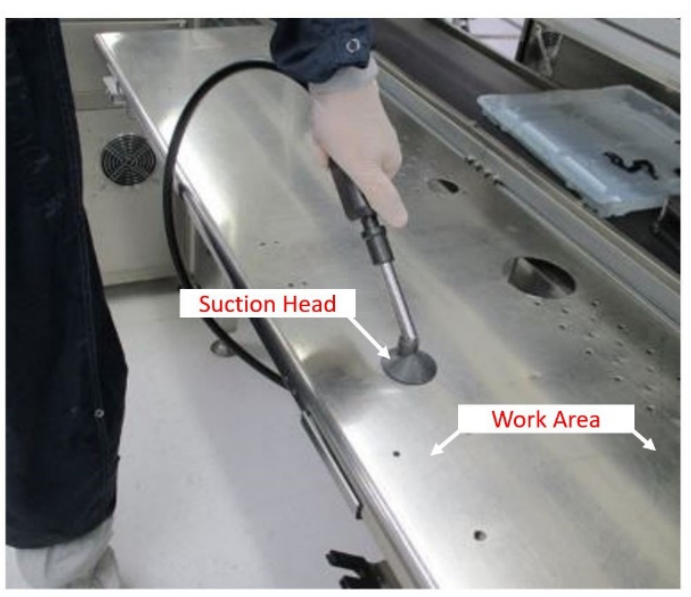

(a)

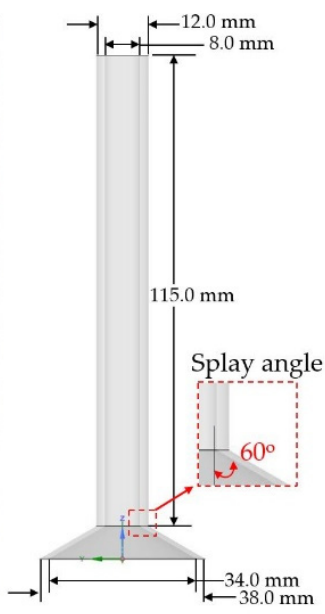

(b)

Figure 2. A suction head: (a) actual model in a factory [12], and (b) simplified fluid model in a simulation. 


\subsection{Simulation}

\subsubsection{Mesh Models}

The fluid models mentioned above were used as prototypes to create mesh models using ICEM software specifically for creating a high-quality mesh model. Figure 3 shows the mesh models used to investigate the airflow (a) in space and (b) $5 \mathrm{~mm}$ above the work area. Both models were constructed as half models with all hexahedrons. The difference was that (a) had more space below the SH than (b). Both models were assigned $y+$ of 1 and a growth rate of 1.2, and then the ICEM software generated the mesh models automatically. The proper mesh models that provide reliable results with the fastest computational time based on mesh independent analysis have $0.86-0.92$ million nodes and 0.89-0.93 million elements as shown in Figure $3 a$, and $0.43-0.47$ million nodes and $0.40-0.44$ million elements as shown in Figure $3 \mathrm{~b}$. Therefore, the proper mesh models have a minimum length of $0.1 \mathrm{~mm}$ and a maximum of $10 \mathrm{~mm}$. We recognized that the estimated velocity of the fastest particles was $5 \mathrm{~m} / \mathrm{s}$ [12], and the desired time step size was $1 \times 10^{-3} \mathrm{~s}$ for the SST $k-\omega$, so the element length recommended by the DPM should be higher than the multiplication between the velocity and time step size [20] which was $5 \mathrm{~mm}$. Thus, the setting of element size as $0.1 \mathrm{~mm}$ in this research covered the recommendation of DP model. According to the mentioned recommendation, the elements of space around and below the SH in Figure $3 \mathrm{~b}$ were smaller than the other regions to accurately capture the airflow and particle traces.

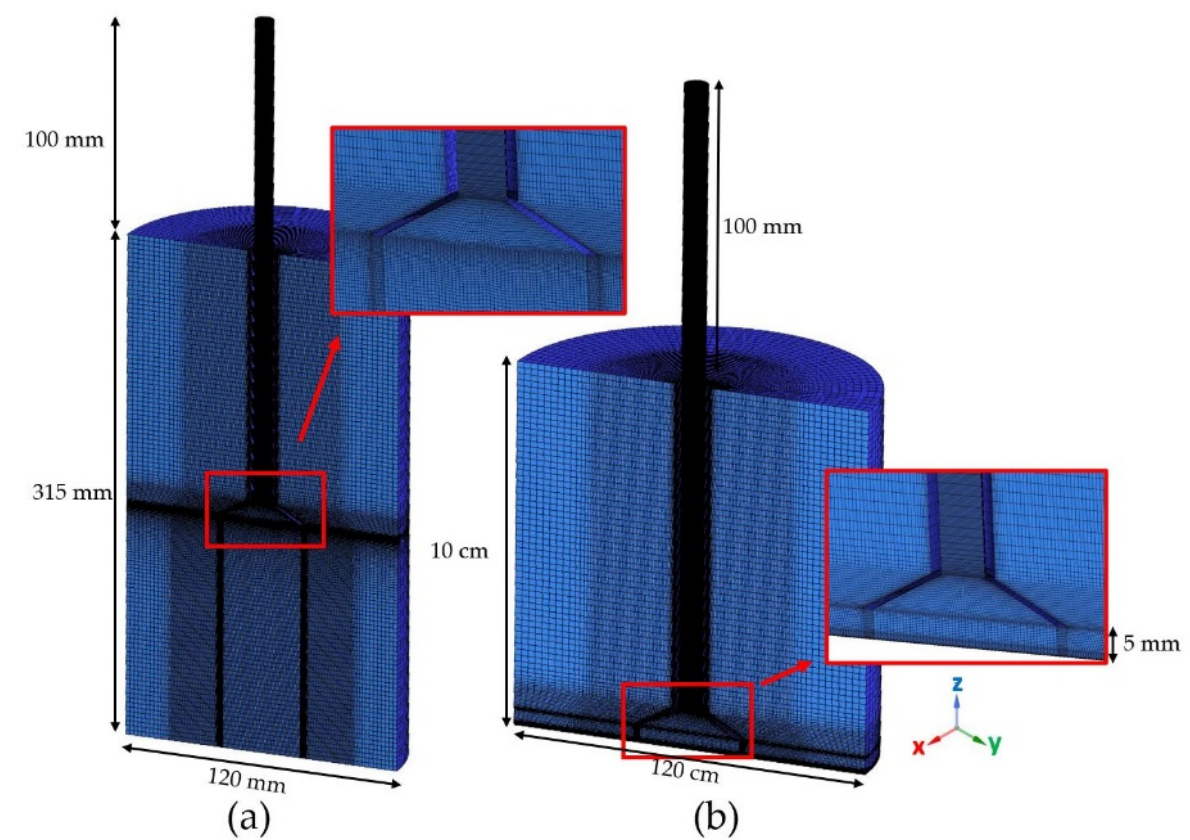

Figure 3. Mesh models for simulation in (a) space and (b) $5 \mathrm{~mm}$ above the work area.

\subsubsection{Boundary Conditions}

The boundary conditions were reported only in the essential settings. For others not mentioned here, we used the default setting of the software. For example, Figure 4 shows the boundary conditions resulting from Figure 3. From the field measurement at the factory, we found that the splay angle of $30^{\circ}$ pressure outside the SH was $101,375 \mathrm{~Pa}$, while the pressure inside the pipe was $91,375 \mathrm{~Pa}$, a difference of $10,000 \mathrm{~Pa}$. Therefore, both pressures were defined as the pressure inlet and pressure outlet, respectively. The symmetry was the area where the airflows were precisely the same, which helps to generate a faster calculation. The air was set to $1255 \mathrm{~kg} / \mathrm{m}^{3}$, an incompressible flow. The noise was generated when the air flowed through and impacted the SH's surface; therefore, the SH was defined as a wall, representing a noise generated by the source in the FW-H model. 


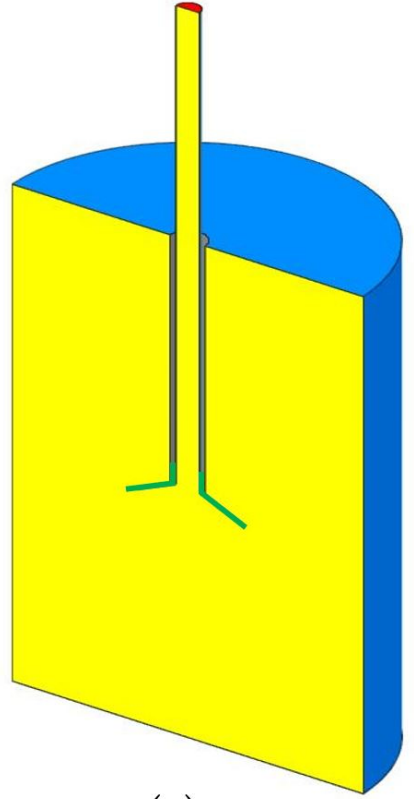

(a)

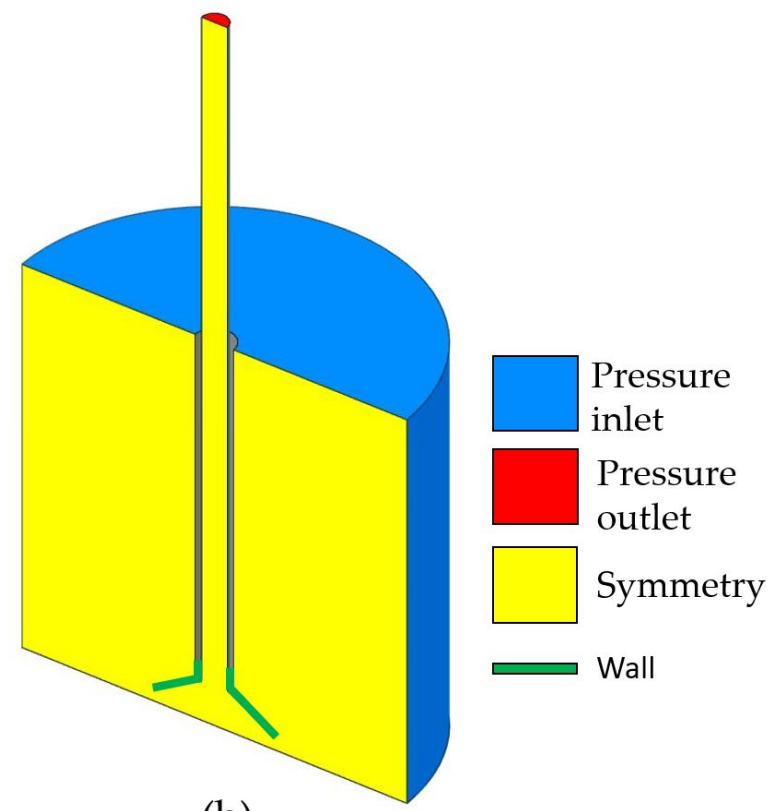

(b)

Figure 4. Boundary conditions for simulation in (a) space and (b) $5 \mathrm{~mm}$ above the work area.

\subsubsection{Software Settings}

To investigate the particle removing performance, we used a one-way simulation with spherical particles of stainless steel of radius $0.5 \mu \mathrm{m}$ and a density of $7500 \mathrm{~kg} /{ }^{3}$ representing the dirt particles in the factory. In the one-way simulation, the airflow was calculated using Equations (1)-(4), and then the results were transferred to the particle trace calculation. The initial positions of 50,000 particles before removal were placed in a circle area with a radius of $6 \mathrm{~cm}$ and were written as a code in the Python programming language. Solving Equations (10) and (11) yielded particle traces and allowed the counting of particles before and after removal during $3 \mathrm{~s}$. The mentioned method of setting was the same method that was successful in our previous work [6,12].

To investigate the noise generation, the SST $k-\omega$ results were forwarded to the LES and the FW-H models. Solving Equations (12)-(15) yielded the $L_{A e q}$ at the desired position during $0.05 \mathrm{~s}$. Tables 1 and 2 report the essential settings for the SST $k-\omega$ and LES simulations, respectively.

Table 1. The essential settings for the SST $k-\omega$ simulation.

\begin{tabular}{cc}
\hline Solver & Pressure Based (Transient) \\
\hline Turbulence model & SST $k$ - $\omega$ \\
\hline Solution method & Coupled (Second-order upwind) \\
\hline Residual & $1 \times 10^{-4}$ \\
\hline Time step size & $1 \times 10^{-3} \mathrm{~s}$ \\
\hline $\begin{array}{c}\text { Number of time steps } \\
\text { (20 iteration/time steps) }\end{array}$ & 3000 steps \\
\hline
\end{tabular}


Table 2. The essential settings for the LES simulation.

\begin{tabular}{cc}
\hline Solver & Pressure Based (Transient) \\
\hline Turbulence model & Large Eddy Simulation (LES) \\
\hline \multirow{2}{*}{ Solution method } & Non-Iterative Time Advancement method \\
\cline { 2 - 2 } & The pressure-velocity coupling method: Fractional Step \\
\cline { 2 - 2 } & Pressure spatial discretization: linear \\
\cline { 2 - 2 } & The gradient discretization: Least squares cell-based scheme \\
\cline { 2 - 2 } Acoustic model & Transient Formulation: Second-Order Implicit \\
\cline { 2 - 2 } & Ffowcs William and Hawkings (FW-H) \\
\hline Residual & Acoustic source: source zone: nozzle wall \\
\hline Time step size & Number of time steps per file $=1000$ \\
\hline Number of time steps & $1 \times 10^{-4}$ \\
\hline $\mathbf{1 0}$ iteration/time steps) & $5 \times 10^{-6} \mathrm{~s}$ \\
\hline
\end{tabular}

\subsection{Experiment}

Figure 5 a shows the CAD models of SHs for various splay angles. Figure $5 b$ shows actual SHs created by 3D printing using the CAD models above as prototypes. The inner surface of all the SHs was coated with wax to make it smooth, similar to the actual surface. The created SHs were employed to measure the air velocity and SPL in the experiment.

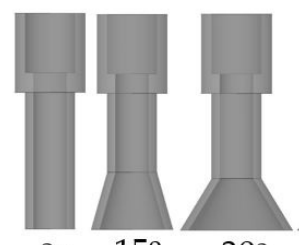

$0^{\circ}$ $15^{\circ}$ $30^{\circ}$

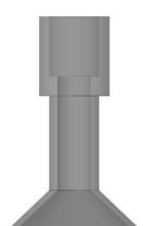

$45^{\circ}$

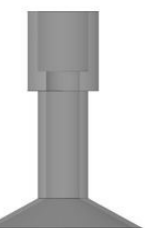

$60^{\circ}$

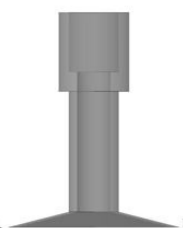

$75^{\circ}$

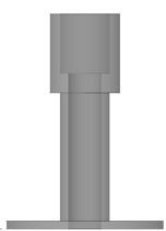

$90^{\circ}$

(a)

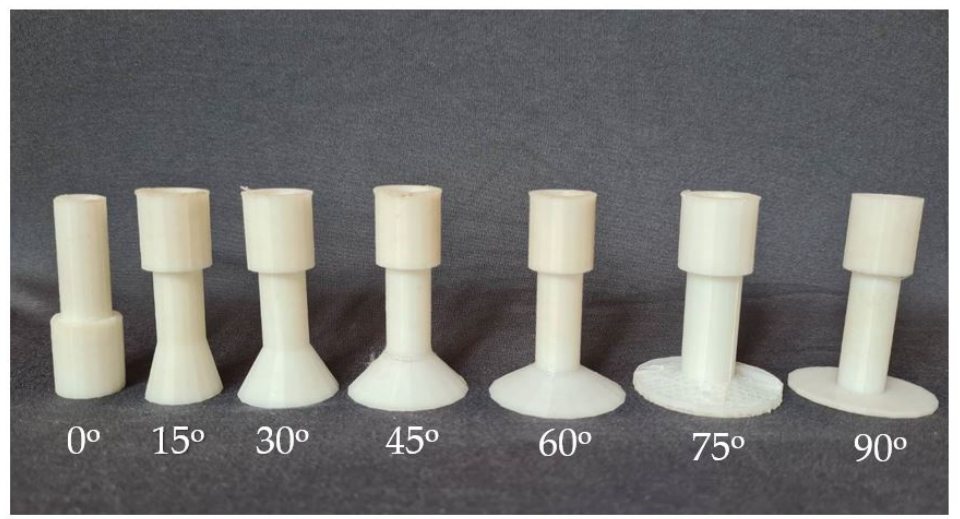

(b)

Figure 5. Suction heads (a) CAD model, and (b) actual models created by 3D printing.

Figure 6a shows the installation of the equipment for air velocity measurement: an actual setup on the left and a schematic diagram on the right. First, the SH was installed at the end of a duct connected to a vacuum pump located far away to assure that the noise generated by the vacuum pump did not interfere with the experiment. Next, the vacuum pump was adjusted and monitored by a pressure gauge until the SH's outside and inside 
pressures corresponded to the boundary conditions mentioned in Section 3.2.2. Finally, a Testo 425 hot-wire anemometer with $\pm 0.03 \mathrm{~m} / \mathrm{s}$ of accuracy was placed at a distance of $5 \mathrm{~mm}$ below the center of $\mathrm{SH}$ to measure the air velocity in space. The measurement was repeated five times.
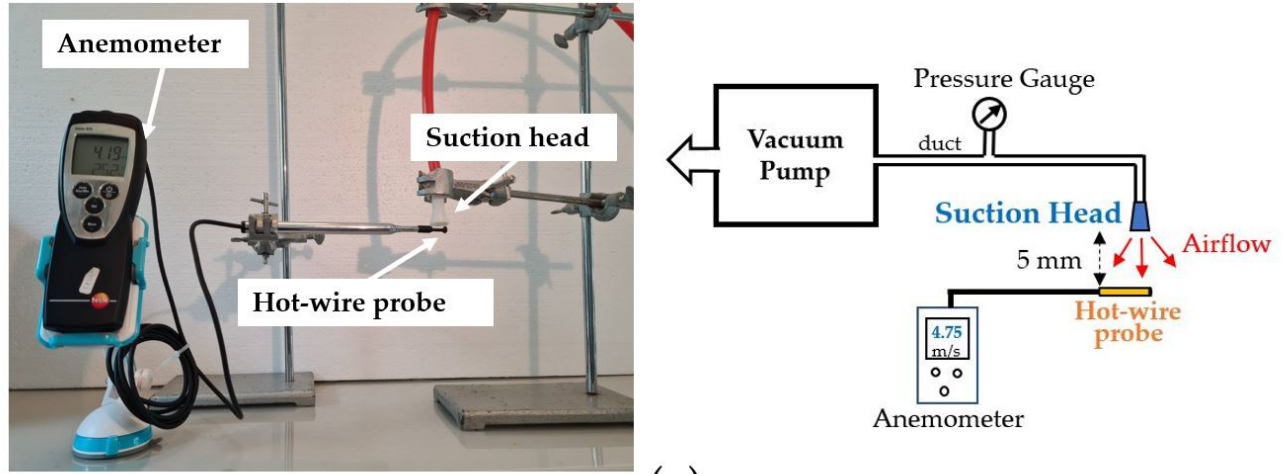

(a)
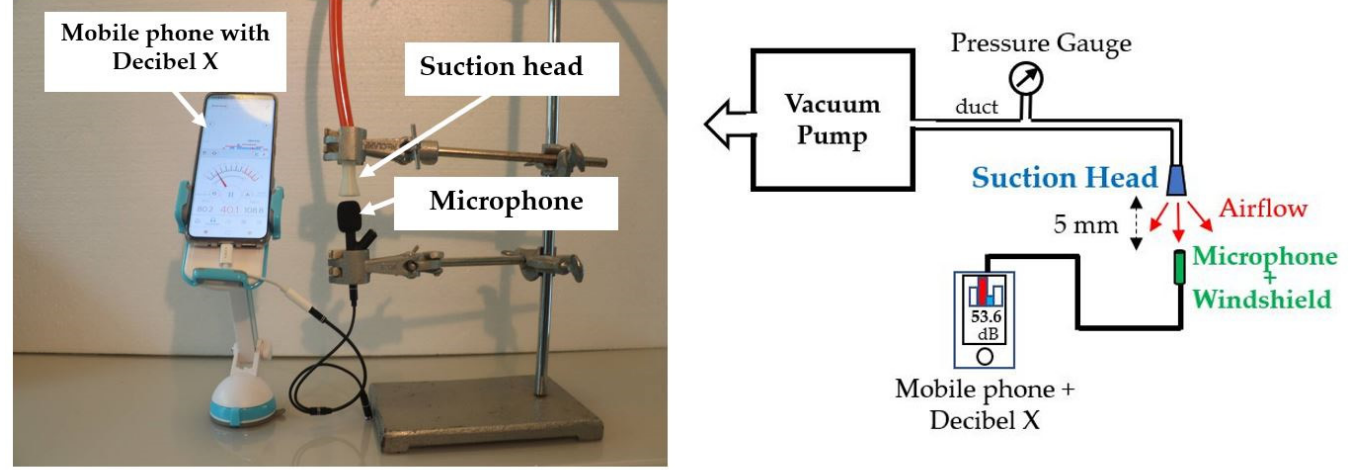

(b)

Figure 6. Actual experimental setups on the left and schematic diagrams on the right for (a) air velocity and (b) sound pressure level measurements.

Figure $6 \mathrm{~b}$ reveals the implementation of the equipment for SPL measurement: an actual setup on the left and a schematic diagram on the right. Similar to the above, the hot-wire anemometer was replaced by a mobile phone with Decibel $X$ v6.3.6. Decibel $X$ is an application that received the highest rating in 2020. It can be used to measure the $L_{\text {Aeq }}$ in the range of 40-85 dB very well, with discrepancies in the range of $0.9-2.3 \mathrm{~dB}$ [29]. The $L_{A e q}$ of frequencies in the range of $1000-4000 \mathrm{~Hz}$ were measured because this range is close to human listening. The microphone used was a Dayton Audio iMM-6, which was suitable for this experiment as it only provided an error of $\pm 2 \mathrm{~dB}$ [30]. In addition, the microphone was encased in a windshield to prevent other noise sources from the environment. Before the experiment, the Decibel $\mathrm{X}$ was calibrated with a precise sound level meter to assure credible outcomes. The Decibel X recorded the frequency and SPL every $0.2 \mathrm{~s}$, a total of $5 \mathrm{~s}$ to display the represented $L_{\text {Aeq }}$ again, the experiment was repeated five times. In fact, we had a basic but precise sound pressure meter, but it could measure only $L_{\text {Aeq }}$. Unfortunately, it could not report the A-weighted level frequency and had a large microphone compared to the diameter of $\mathrm{SH}$, making it easier to affect the environment. Therefore, the Decibel $\mathrm{X}$, Dayton, and the supported instruments were applied, as shown in Figure 6b. The decibel $\mathrm{X}$ required a post-processing procedure for analysis.

\section{Results and Discussion}

This section is divided into two subsections: validation and a suitable SH. First, the simulation and experimental results are reported to confirm the credibility of the research 
methodology. Later, all the results are analyzed along with the changes to some parameters that were introduced to find the suitable SH.

\subsection{Validation}

Figure 7 compares the air velocities from the simulation and the experiment for the suction in space displayed in Figure 6a. The comparison shows good consistency, with the simulation error in the range of $1.52-3.95 \%$ compared to the average value. The SH's shapes affected the air velocity at the measured point. The simulation results reveal that $90^{\circ} \mathrm{SH}$ gave the highest air velocity of $5.78 \mathrm{~m} / \mathrm{s}$, while $45^{\circ} \mathrm{SH}$ gave the lowest value of $3.52 \mathrm{~m} / \mathrm{s}$. The error may be that the wind speed flowing out of the $\mathrm{SH}$ was unstable and changed slightly, but we used the constant pressure in the boundary condition. Hence, using the transient pressure profile setting as the boundary condition will decrease the error as suggested in [6]. Moreover, increasing the number of measurements is expected to reduce the error. The error bars represented the standard deviation from the experiment were in the range of $0.13-0.23 \mathrm{~m} / \mathrm{s}$, higher than the uncertainty (resolution) of hot-wire anemometer of $\pm 0.03 \mathrm{~m} / \mathrm{s}$ (Testo 425 ). However, all the simulation results were still within the error bar of height, so the simulation results of air velocity are reliable.

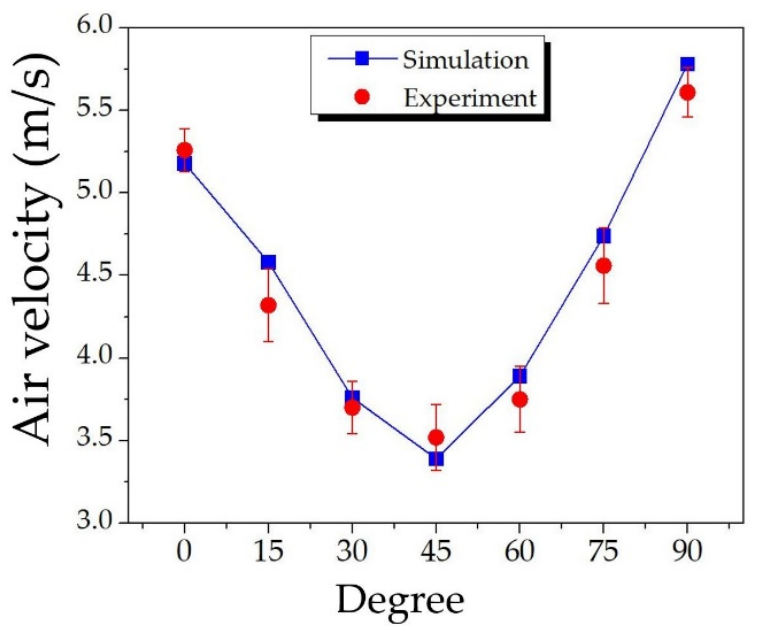

Figure 7. Comparison between the simulated and measured air velocities.

With the same boundary condition as above, Table 3 shows the simulation (Sim.) and experimental (Exp.) results from the experiment displayed in Figure $6 \mathrm{~b}$ for $1 / 3$ octave band frequencies in the $1000-4000 \mathrm{~Hz}$ range of $15^{\circ}, 45^{\circ}$, and $90^{\circ} \mathrm{SHs}$. In the first column, 890.9-1125.5 Hz, 1122.6-1414.2 Hz, and so on are the frequency ranges of the theoretical A-weighted SPL. The standard frequencies reported by Decibel $X$ are in parentheses. The second column shows the simulation frequencies calculated by the LES and FW-H models in CFD. The parentheses report a discrepancy relative to the standard frequency, which ranges from 0.3 to $1 \%$. Thus, again, the simulation frequencies were still within the theoretical frequency range and are reliable. We use the word "discrepancy" because both the simulation and experiment results had their own errors. Therefore, it is impossible to determine which one is the most accurate, unlike the anemometer measurement, which we believe provides highly accurate results compared to the simulation. In columns 3-8, the $L_{A e q}$ of simulation and measurement are reported. All the experimental results were less than all of the simulations; we expected this because of the windshield. Without the windshield, we found that the $L_{A e q}$ was unstable due to the noise generated by the environment, so we preferred to install the windshield. The bottom row reports the total $L_{\text {Aeq }}$ from the experiment measured by Decibel $X$ and the simulation calculated using Equation (16) and the data above in the same column. The $L_{A e q}$ in the asterisk reported by Decibel $X$ included the sound pressure level from other frequencies outside Table 3. Their values are close to those obtained in simulation, implying that noise due to other 
frequencies had little effect on the SPL since $1000-4000 \mathrm{~Hz}$ is the range frequency of human listening, as expected. Based on the results in Table 3, we believe that the simulation results of $L_{\text {Aeq }}$ are also credible.

Table 3. Equivalent A-weighted sound pressure level at $5 \mathrm{~mm}$ below the center point of SH.

\begin{tabular}{|c|c|c|c|c|c|c|c|}
\hline \multirow{2}{*}{\multicolumn{2}{|c|}{$\begin{array}{l}\text { 1/3 Octave Band } \\
\text { Frequency }(\mathrm{Hz})\end{array}$}} & \multicolumn{6}{|c|}{$L_{A e q}(\mathrm{dBA})$} \\
\hline & & \multicolumn{2}{|c|}{$15^{\circ}$} & \multicolumn{2}{|c|}{$45^{\circ}$} & \multicolumn{2}{|c|}{$90^{\circ}$} \\
\hline Exp. (Standard) & Sim. (Discrepancy\%) & Exp. & Sim. & Exp. & Sim & Exp. & Sim. \\
\hline $890.9-1125.5$ (1000) & $1006(0.6 \%)$ & $54.2 \pm 5.1$ & 55.6 & $32.2 \pm 7.2$ & 34.2 & $69.2 \pm 5.5$ & 72.5 \\
\hline $1122.6-1414.2(1250)$ & $1260(0.8 \%)$ & $50.2 \pm 4.7$ & 54.5 & $32.4 \pm 6.1$ & 34.9 & $68.4 \pm 5.2$ & 71.7 \\
\hline $1414.3-1781.8$ (1600) & $1600(0.0 \%)$ & $53.1 \pm 4.8$ & 54.2 & $30.2 \pm 6.0$ & 31.3 & $67.5 \pm 5.7$ & 71.8 \\
\hline $1781.9-2244.9(2000)$ & $2020(1.0 \%)$ & $54.0 \pm 5.2$ & 56.1 & $29.8 \pm 5.3$ & 32.8 & $67.8 \pm 5.3$ & 70.3 \\
\hline $2245.0-2828.4(2500)$ & $2520(0.8 \%)$ & $53.2 \pm 4.8$ & 56.9 & $27.9 \pm 6.8$ & 30.3 & $68.2 \pm 5.4$ & 71.6 \\
\hline $2828.5-3563.6(3150)$ & $3175(0.8 \%)$ & $53.4 \pm 5.0$ & 57.3 & $27.5 \pm 5.4$ & 28.9 & $67.8 \pm 5.3$ & 72.9 \\
\hline $3563.6-4489.8(4000)$ & $4010(0.3 \%) *$ & $50.3 \pm 4.7$ & 52.9 & $27.8 \pm 6.7$ & 28.6 & $70.3 \pm 5.5$ & 73.9 \\
\hline \multicolumn{2}{|c|}{ Total $L_{\text {Aeq }}$} & $53.6 \pm 5.6^{*}$ & 55.6 & $30.8 \pm 4.6^{*}$ & 32.2 & $69.2 \pm 6.1 *$ & 72.2 \\
\hline
\end{tabular}

Increasing the credibility and reducing the simulation discrepancy can be achieved by improving the number of time steps and the time step size to cover a longer time. In addition, enhancing the accuracy and minimizing the experimental errors can be approached using a high-precision anemometer and sound pressure level instruments to improve the measurement with more repetitions. However, we believe that such improvements will not affect our conclusions since the simulation and experiment described above have already yielded reliable and sufficient results. Therefore, the research methodology could be applied to determine the suitable SH shape in the next subsection.

\subsection{A Suitable SH Shape}

This section has been divided into two parts: suction performance and noise generation. The results from two parts were analyzed to find a suitable $\mathrm{SH}$.

\subsubsection{Suction Performance}

As described in Sections 3.2.2 and 3.2.3, the stainless-steel particles represented the dirt particles to be cleaned in the factory. Therefore, solving Equation (5), the suspension velocity $\left(\mathrm{v}_{\mathrm{s}}\right)$ was $1.0114 \mathrm{~m} / \mathrm{s}$. Figure 8 shows the contour plots of the cleaning region in 2D in a center plane simulated by the SST $k-\omega$, that is, the region with air velocity perpendicular to the work area higher than $\mathrm{v}_{\mathrm{S}}$ for the splay angles of (a) $0^{\circ}$, (b) $15^{\circ}$, (c) $30^{\circ}$, (d) $45^{\circ}$, (e) $60^{\circ}$, (f) $75^{\circ}$, and (g) $90^{\circ}$. The grey color is the unclean region; the dirt particles cannot be removed. The small vectors in the black color confirmed that the air was sucked into the $\mathrm{SH}$. The red color is the region with an air velocity higher than $10 \mathrm{~m} / \mathrm{s}$. The simulation results reveal that different $\mathrm{SH}$ shapes gave different cleaning region shapes; they had unequal performances. For (a)-(g), the cleaning regions in space were (a) $354.96 \mathrm{~mm}^{2}$, (b) $420 \mathrm{~mm}^{2}$, (c) $436.64 \mathrm{~mm}^{2}$, (d) $474.80 \mathrm{~mm}^{2}$, (e) $477.09 \mathrm{~mm}^{2}$, (f) $476.48 \mathrm{~mm}^{2}$, and $481.82 \mathrm{~mm}^{2}$. Similarly, Figure 9 shows the cleaning regions for the pressures of $10,000 \mathrm{~Pa}, 50,000 \mathrm{~Pa}$, and $100,000 \mathrm{~Pa}$. Note that 10,000 $\mathrm{Pa}$ is the difference between the pressure inlet and pressure outlet. When increasing the pressure difference or enhancing the vacuum pump's level, the cleaning region would be enlarged; particles could be removed in a larger area, as expected. The higher the pressure, the better the cleaning performance. From Figures 8 and 9 , the $0^{\circ}$ $\mathrm{SH}$ provided the smallest cleaning region consistent with the report in [12], while $45^{\circ}, 60^{\circ}$, $75^{\circ}$, and $90^{\circ} \mathrm{SHs}$ provided similar cleaning region sizes and were larger than the others. Therefore, they were the shapes that were potential suitable models that needed to be investigated further. The SHs with small splay angles are less efficient because they also suck the air on the top, which is not the target area in the cleaning process. Powerful SHs are often designed to have just the proper splay angle [12-18]. 


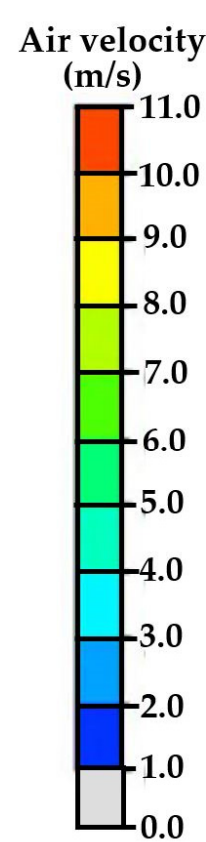

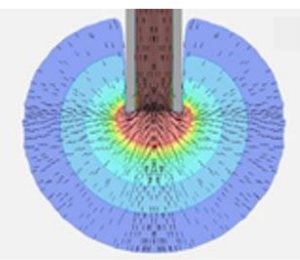

(a)

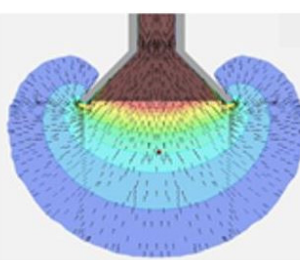

(d)

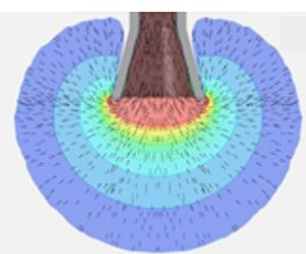

(b)

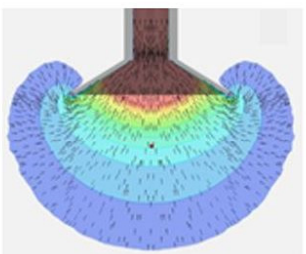

(e)

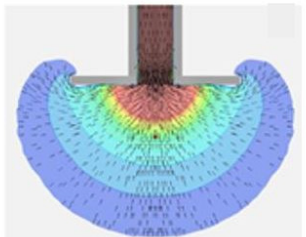

(g)

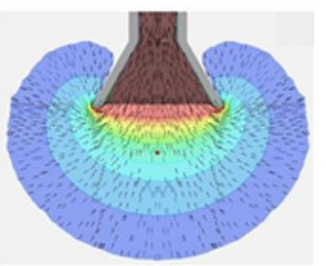

(c)

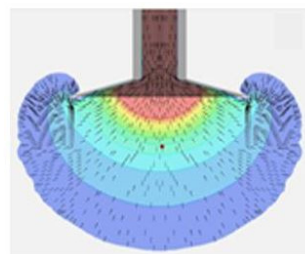

(f)

Figure 8. Th cleaning regions for the splay angles of (a) $0^{\circ}$, (b) $15^{\circ}$, (c) $30^{\circ}$, (d) $45^{\circ}$, (e) $60^{\circ}$, (f) $75^{\circ}$, and (g) $90^{\circ}$.

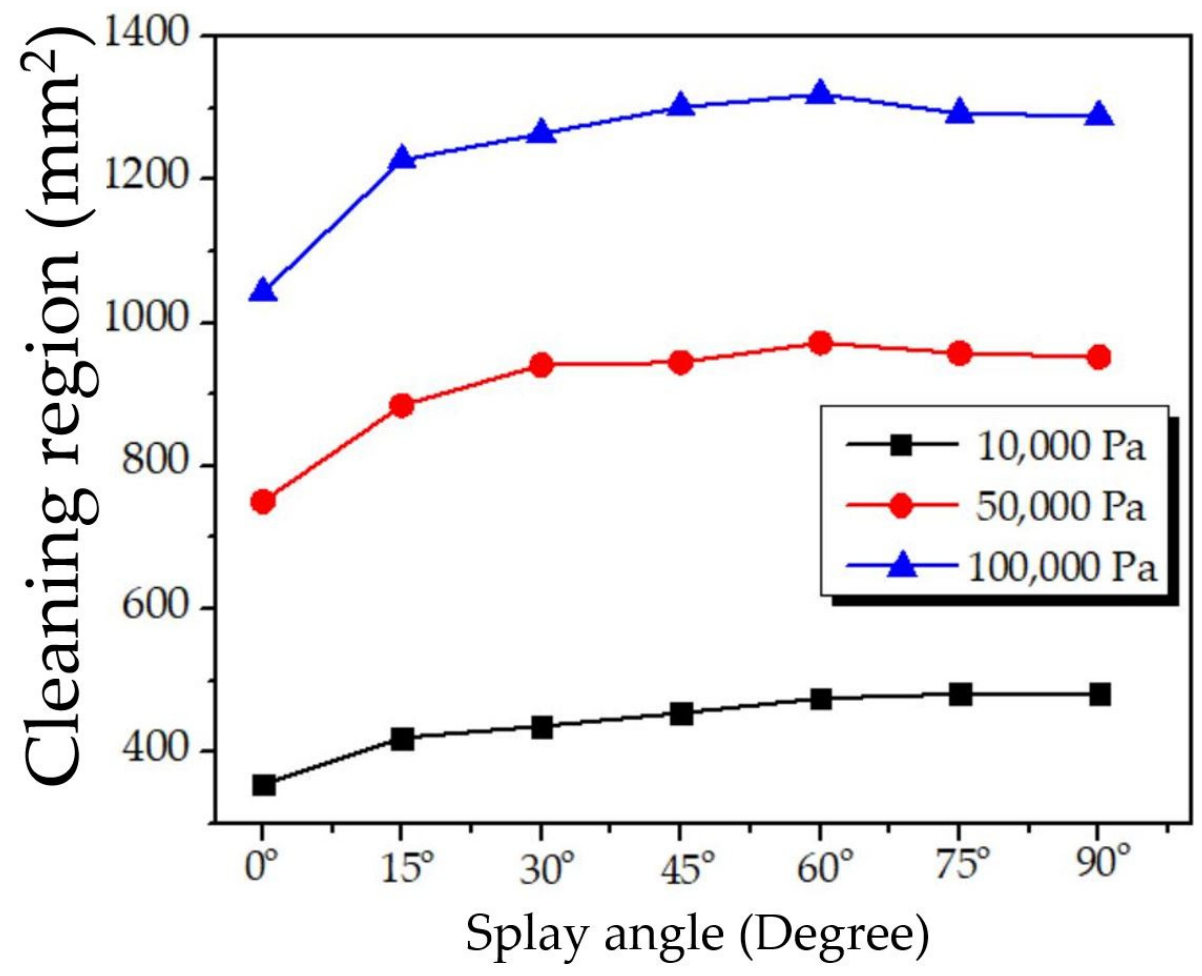

Figure 9. The cleaning regions for the different pressures.

Figure $10 \mathrm{a}-\mathrm{g}$ reveal the cleaning regions in a side view of the work area with a different pressure of $10,000 \mathrm{~Pa}$ for the $0^{\circ}-90^{\circ} \mathrm{SHs}$, respectively. Similarly, Figure $11 \mathrm{a}-\mathrm{g}$ show the view of the cleaning regions from the top, displayed using the $\mathrm{v}_{\mathrm{S}}$ perpendicular to the work area. The circle area with a radius of $6 \mathrm{~cm}$ is a target region expected to be cleaned. The cleaning region is the area represented by color. On the contrary, the grey color is where particles are not sucked into the $\mathrm{SH}$, and no cleaning occurs. To the naked eye, it 
is impossible to determine the sizes of the cleaning regions in Figure 11, so a computer needs to be employed to help analyze the data. This is discussed together with the results of particle trace next.

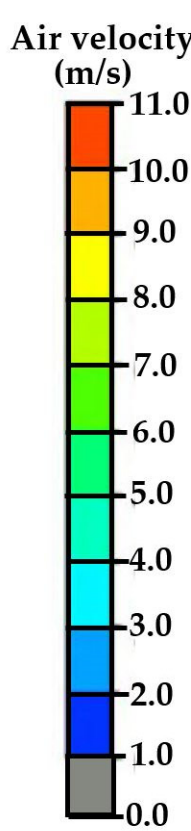

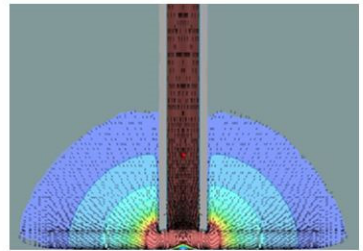

(a)

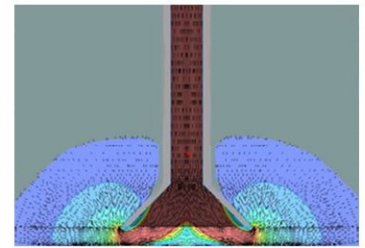

(d)

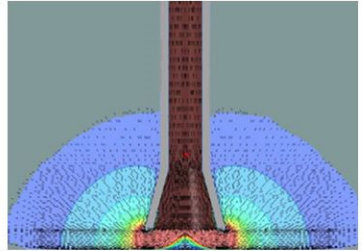

(b)

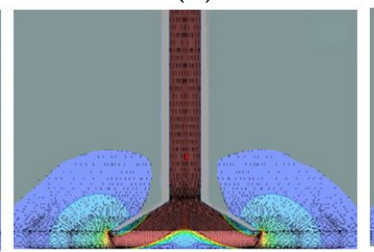

(e)

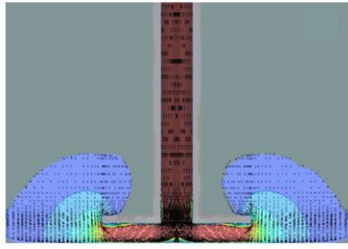

(g)

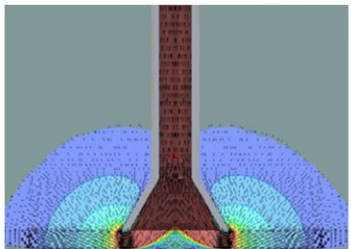

(c)

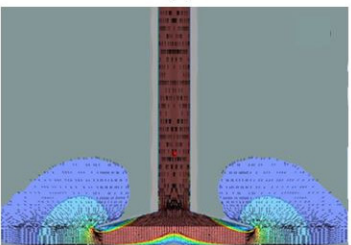

(f)

Figure 10. The cleaning regions in a side view of the work area for the splay angles of $(\mathbf{a}) 0^{\circ},(\mathbf{b}) 15^{\circ}$, (c) $30^{\circ}$, (d) $45^{\circ}$, (e) $60^{\circ}$, (f) $75^{\circ}$, and (g) $90^{\circ}$.

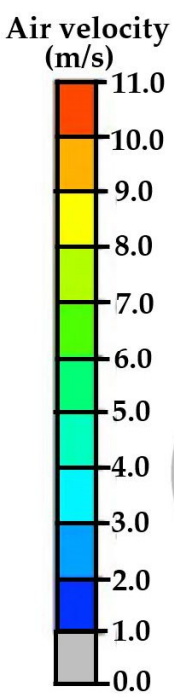

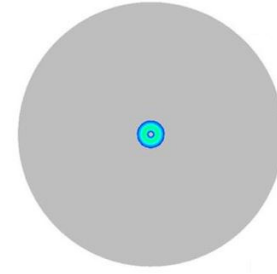

(a)

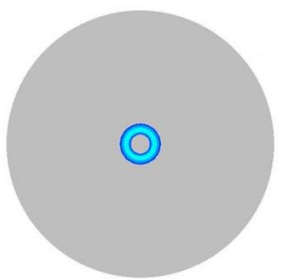

(b)

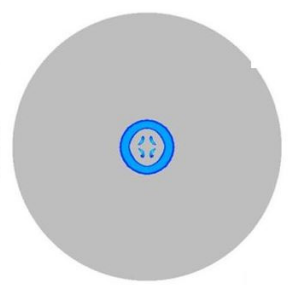

(c)

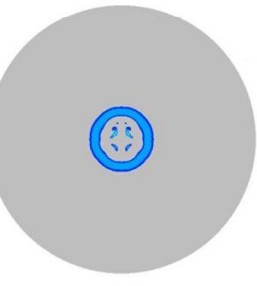

(d)

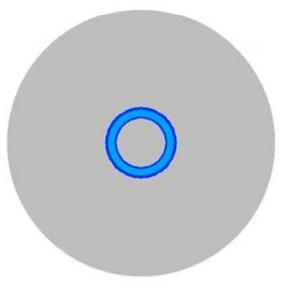

(e)

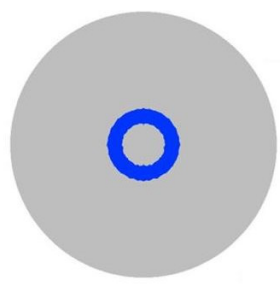

(f)

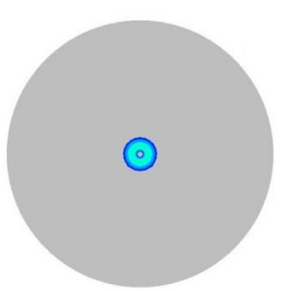

(g)

Figure 11. The cleaning regions in a top view of the work area for the splay angles of (a) $0^{\circ},(\mathbf{b}) 15^{\circ}$, (c) $30^{\circ}$, (d) $45^{\circ}$, (e) $60^{\circ}$, (f) $75^{\circ}$, and (g) $90^{\circ}$.

Figure 12 shows the samples of the remaining stainless steel particle traces after $3 \mathrm{~s}$ of cleaning, simulated using the SST $k-\omega$ and DPM models for (a) $0^{\circ}$, (b) $30^{\circ}$, and (c) $45^{\circ}$. Again, the color scale reports the particle velocity, and the streak presents its trace. The closer the position to the $\mathrm{SH}$, the higher the removal particle velocity, as expected. With careful observation, it can be seen that the $45^{\circ} \mathrm{SH}$ had the fewest particles remaining in the work area; that is, it removed the most particles, followed by the $30^{\circ} \mathrm{SH}$, and finally, the $0^{\circ}$ $\mathrm{SH}$ was the worst at removing the particles. In fact, we simulated the cleaning process of all the SHs, but we have shown only three samples because the resulting images were very 
similar. Displaying all the SHs does not aid analysis and may be confusing because the remaining particles cannot be counted visually. Therefore, a computer was used to help us accurately count the number of remaining and sucked-up particles. Again, we will discuss them next.

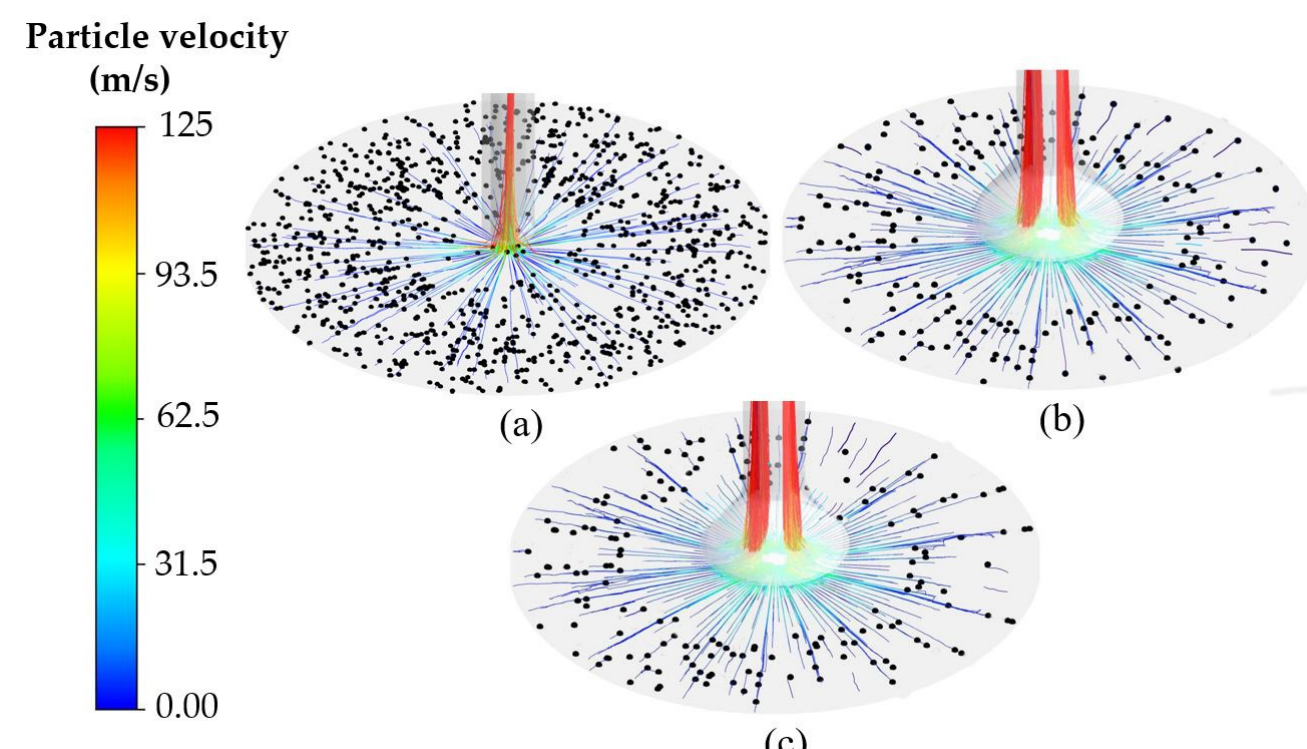

Figure 12. The remaining particles after $3 \mathrm{~s}$ of the cleaning process of the splay angles of (a) $0^{\circ}$, (b) $30^{\circ}$, (c) $45^{\circ} \mathrm{SHs}$

Figure 13 shows the cleaning regions from Figure 11 and the particle removing performance from Figure 12 for various SH shapes. The particle removing performance is the percentage of particles present in the work area calculated before and after cleaning. Again, the comparison revealed consistency. The SH shapes affected the cleaning region and the particle removing performance. As expected, the $30^{\circ} \mathrm{SH}$ was better than the $0^{\circ} \mathrm{SH}$, consistent with the report in [12], but it was not the best. The $75^{\circ} \mathrm{SH}$ was the model with the best particle removing performance of $84.66 \%$ with a cleaning region of $270 \mathrm{~mm}^{2}$.

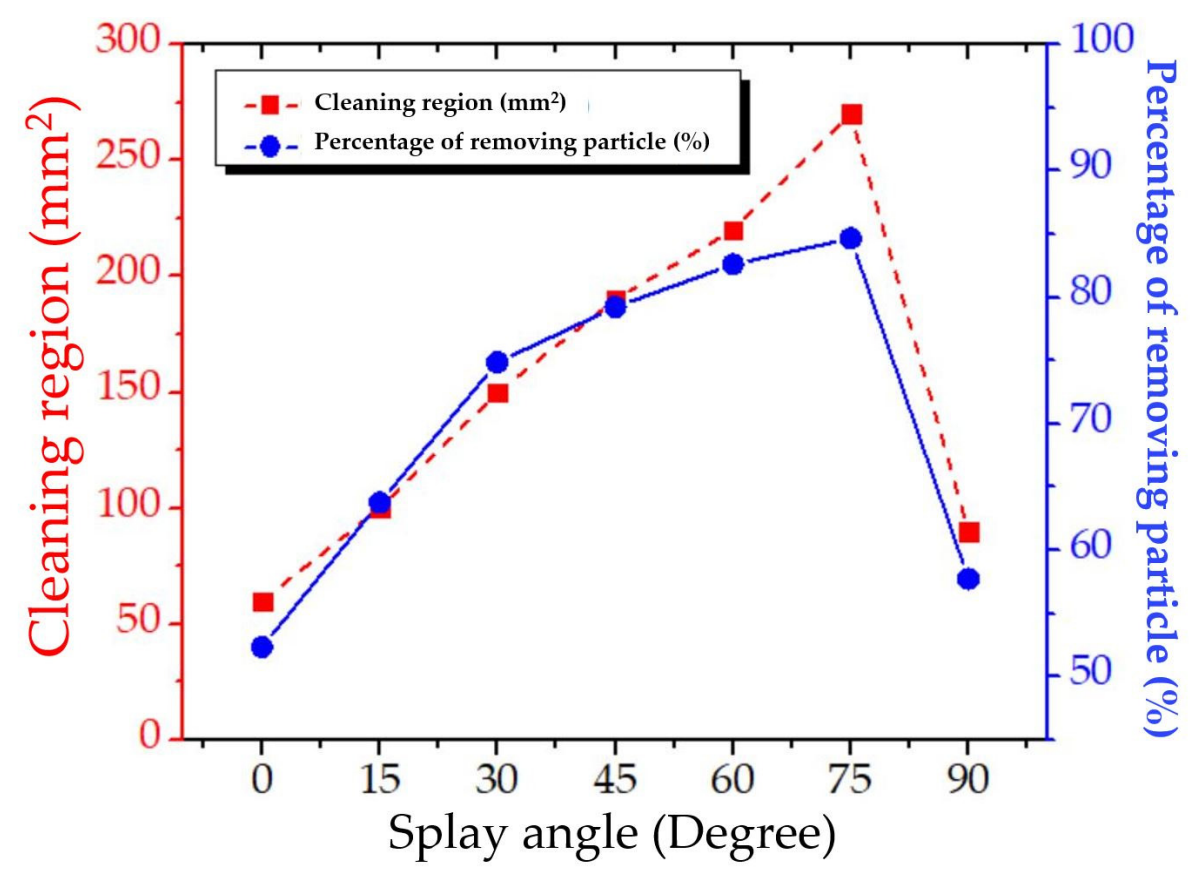

Figure 13. The cleaning regions and percentage of removing particles for various $\mathrm{SH}$ shapes. 


\subsubsection{Noise Generation}

Figure 14 shows the $L_{A e q}$ and frequencies simulated with the LES and FW-H models for various $\mathrm{SH}$ shapes. All simulation results confirm that the $\mathrm{SH}$ shapes affected the $L_{\text {Aeq }}$. For all frequencies, the $90^{\circ} \mathrm{SH}$ generated the highest noise, $45^{\circ} \mathrm{SH}$ generated the lowest. Comparing Figures 7 and 8, the noise was related to the air velocity. The higher the air velocity, the higher the noise generation, as expected. The relationship is confirmed by Equations (12)-(14) in the FW-H model, which shows that air velocity $(u)$ is a significant factor of noise generation. In summary, Table 4 reports the results from Figures 13 and 14.

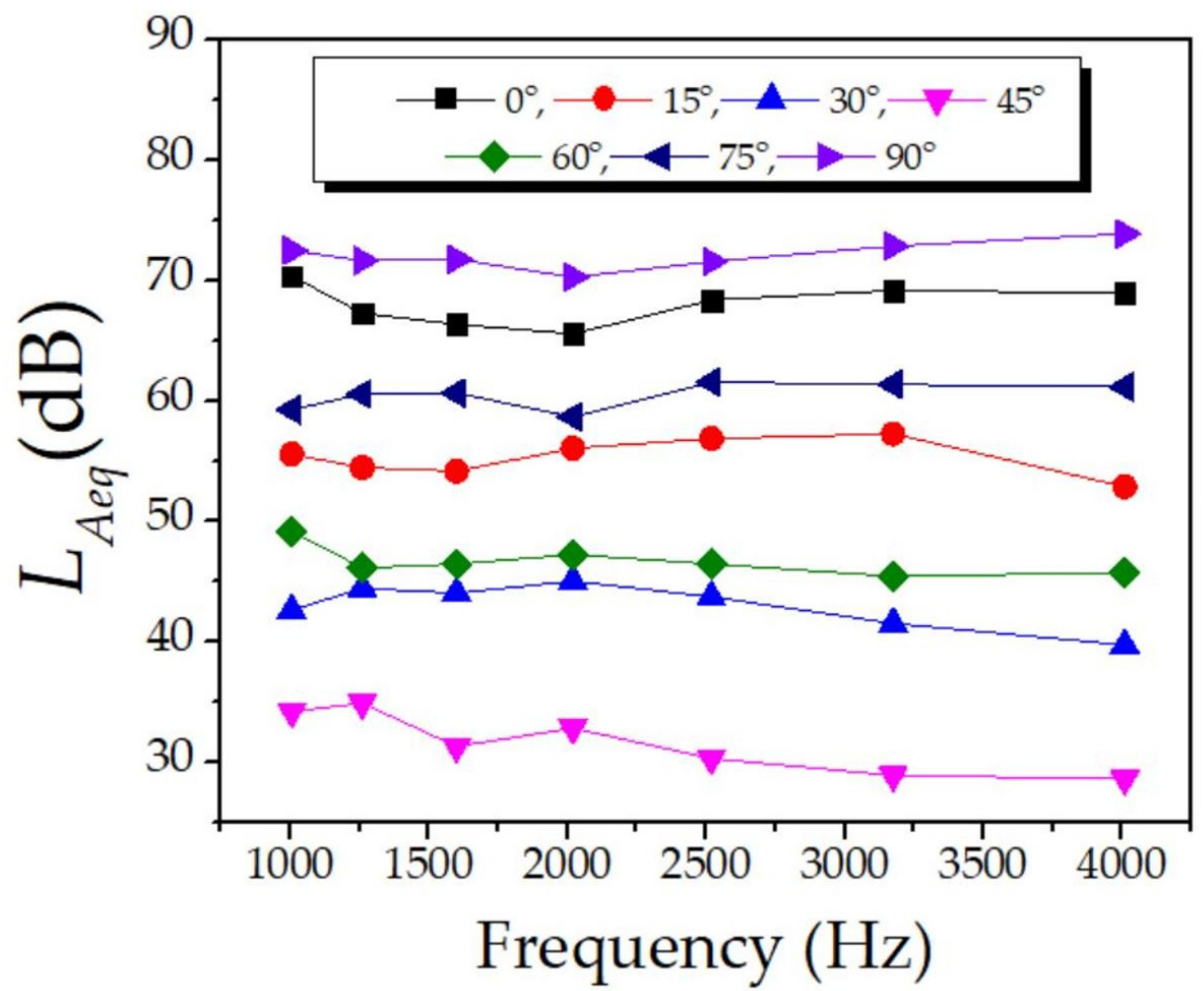

Figure 14. The equivalent A-weighted SPLs $\left(L_{A e q}\right)$ and frequencies for various SH shapes.

Table 4. The performance of the SHs.

\begin{tabular}{cccc}
\hline \multirow{2}{*}{ Splay Angle } & \multicolumn{2}{c}{ Cleaning Performance } & \\
\cline { 2 - 3 } & Cleaning Region $\left(\mathbf{m m}^{\mathbf{2}}\right)$ & $\begin{array}{c}\text { Particle Removing } \\
\text { Performance (\%) }\end{array}$ & Total $L_{\text {Aeq }}(\mathbf{d B})$ \\
\hline $0^{\circ}$ & 60 & 52.37 & 68.3 \\
$15^{\circ}$ & 100 & 63.79 & 55.6 \\
$30^{\circ}$ & 150 & 74.86 & 43.3 \\
$45^{\circ}$ & 190 & 79.23 & 32.2 \\
$60^{\circ}$ & 220 & 82.61 & 46.8 \\
$75^{\circ}$ & 270 & 84.66 & 60.6 \\
$90^{\circ}$ & 90 & 57.74 & 72.2 \\
\hline
\end{tabular}

Although the $75^{\circ} \mathrm{SH}$ had the largest cleaning region and the best particle removing performance, it generated high amounts of noise. On the other hand, the $45^{\circ} \mathrm{SH}$ had the lowest noise but moderated the cleaning region of $190 \mathrm{~mm}^{2}$. It had a removing performance of $79.23 \%$, and the lowest total $L_{A e q}$ of $32.2 \mathrm{~dB}$. In our opinion, it stands out from the other shapes because it had a particle removing performance of $5.43 \%$ and a total $L_{A e q}$ of 28.4 less than the $75^{\circ} \mathrm{SH}$. Therefore, it is well balanced in terms of particle removing performance and noise generation. Additionally, the $45^{\circ} \mathrm{SH}$ had $40 \mathrm{~mm}^{2}$ more cleaning region, a $4.37 \%$ higher particle removing performance, and produced $11.1 \mathrm{~dB}$ less total $L_{A e q}$ than the $30^{\circ}$ 
SH currently used in the problematic factory. Therefore, from the results reported in Figures $7-14$, we concluded that the $45^{\circ} \mathrm{SH}$ is a suitable shape for the cleaning process of the factory. The finding of this research has been forwarded to the factory. As a result, it was accepted and implemented in the actual cleaning process.

\section{Conclusions}

To improve the cleaning process in a factory, we proposed new shapes of $\mathrm{SH}$ with splay angles of $15^{\circ}, 45^{\circ}, 60^{\circ}, 75^{\circ}$, and $90^{\circ}$, including $0^{\circ}$ and $30^{\circ}$ from previous work. A total of seven models were used to investigate the particle removing performance and sound noise generation using CFD in a transient state. The investigation was divided into two usage situations: in space and $5 \mathrm{~mm}$ above the work area. First, the SST $k-\omega$ turbulence and DP models were employed to determine the air velocity, cleaning region, suspension velocity, and particle trace. Then, the LES and FW-H models were used to calculate SPL and frequency generated by various shapes of SH. Next, the simulated air velocity was validated by a hot-wire anemometer, while the simulated SPL and frequency were confirmed by a Decibel $X$, an application in a mobile phone, so the simulation results were credible. Then, all the results were analyzed in both usage situations and showed that the shape of $\mathrm{SH}$ affected the cleaning region, particle removing performance, and noise generation, as expected. The $90^{\circ} \mathrm{SH}$ generated the highest amount of annoying noise, but the $45^{\circ} \mathrm{SH}$ created the lowest. The $75^{\circ} \mathrm{SH}$ gave the largest cleaning region; however, the $0^{\circ} \mathrm{SH}$ provided the smallest. The $75^{\circ} \mathrm{SH}$ had the highest particle removing performance, yet the $0^{\circ} \mathrm{SH}$ had the worst. The more pressure used for cleaning, the larger the cleaning region and the greater the particle removing performance. The higher the air velocity released by the $\mathrm{SH}$, the greater the noise generation. Finally, all results were analyzed. We concluded that the $45^{\circ} \mathrm{SH}$ was the most suitable shape for the cleaning process because it stood out in particle removing performance and noise generation, and was better than the previous shape.

Author Contributions: Conceptualization, J.T. and J.K.; methodology, J.T. and J.K.; software, J.T., W.T. and J.K.; validation, J.T. and J.K., formal analysis, J.T.; investigation, J.T.; writing-original draft preparation, J.T.; writing-review and editing, J.T.; project administration, J.T.; funding acquisition, J.T. All authors have read and agreed to the published version of the manuscript.

Funding: The fund was sponsored by Research and Researchers for Industry (RRI), a grant number MSD60I0126.

Institutional Review Board Statement: Not applicable.

Informed Consent Statement: Not applicable.

Data Availability Statement: No additional data available.

Acknowledgments: This research was supported by the College of Advanced Manufacturing Innovation, King Mongkut's Institute of Technology Ladkrabang, and Seagate Technology (Thailand) Ltd.

Conflicts of Interest: The authors declare that there are no conflict of interest for this article.

\section{References}

1. ISO. Cleanrooms and Associated Controlled Environment_Part 1: Classification of Air Cleanliness; ISO No. 146441-1; ISO: Geneva, Switzerland, 1999.

2. Thongsri, J. A Successful CFD-Based Solution to a Water Condensation Problem in a Hard Disk Drive Factory. IEEE Access 2017, 5, 10795-10804. [CrossRef]

3. Sandle, T. Distribution of Particles within the Cleanroom: A Review of Contamination Control Considerations. J. GXP Compliance 2017, 21, 1-10.

4. Naosungnoen, J.; Thongsri, J. Airflow and Temperature Simulation in a Big Cleanroom to Reduce Contamination in an HDD Manufacturing Factory. IOP Conf. Ser. Mater. Sci. Eng. 2018, 361, 012025. [CrossRef]

5. Romano, F.; Milani, S.; Joppolo, C.M. Airborne Particle and Microbiological Human Emission Rate Investigation for Cleanroom Clothing Combinations. Build. Environ. 2020, 180, 106967. [CrossRef] 
6. Thongsri, J. A Problem of Particulate Contamination in an Automated Assembly Machine Successfully Solved by CFD and Simple Experiments. Math. Probl. Eng. 2017, 2017, 6859852. [CrossRef]

7. Khaokom, A.; Thongsri, J.; Kaewkhaw, P. A CFD Investigation of Airflow in a Hard Disk Drive Production Line to Detect The Cause(s) of Contamination and Its Mitigation. In Proceedings of the 2017 IEEE 3rd International Conference on Engineering Technologies and Social Sciences (ICETSS), Bangkok, Thailand, 7-8 August 2017; pp. 1-4.

8. Puangburee, L.; Busayaporn, W.; Kaewbumrung, M.; Thongsri, J. Evaluation and Improvement of Ventilation System Inside Low-Cost Automation Line to Reduce Particle Contamination. ECTI Trans. Electr. Eng. Electron. Commun. 2020, 18, 35-44. [CrossRef]

9. Zhivov, A.; Skistad, H.; Mundt, E.; Posokhin, V.; Ratcliff, M.; Shilkrot, E.; Strongin, A.; Li, X.; Zhang, T.; Zhao, F.; et al. Chapter 7-Principles of Air and Contaminant Movement Inside and Around Buildings. In Industrial Ventilation Design Guidebook, 2nd ed.; Goodfellow, H.D., Kosonen, R., Eds.; Academic Press: Cambridge, MA, USA, 2020; pp. 245-370.

10. Jai-Ngam, N.; Tangchaichit, K. Simulation of Airflow inside a Computer Hard Disk Drive to Develop an Impinging Air Jet Particle Detachment System for Cleaning Head Stack Assemblies. IEEE Trans. Magn. 2018, 54, 1-8. [CrossRef]

11. Yimsiriwatana, N.; Jearsiripongkul, T. Airflow Simulation of Particle Suction in Hard Disk Drives Manufacturing Process. Int. Rev. Model. Simul. 2011, 4, 429-435.

12. Khongsin, J.; Thongsri, J. Numerical Investigation on the Performance of Suction Head in a Cleaning Process of Hard Disk Drive Factory. ECTI Trans. Electr. Eng. Electron. Commun. 2020, 18, 28-34. [CrossRef]

13. Dalla, V.J.M. Exhaust Hoods; Industrial Press: New York, NY, USA, 1952.

14. Garrison, R.P. Nozzle Performance and Design for High Velocity/Low Volume Exhaust Ventilation; ProQuest Information \& Learning: Ann Arbor, MI, USA, 1977.

15. Fletcher, B. Centreline Velocity Characteristics of Rectangular Unflanged Hoods and Slots Under Suction*®. Ann. Occup. Hyg. 1977, 20, 141-146. [CrossRef] [PubMed]

16. Tyaglo, I.G.; Shepelev, I.A. Air Flow Near Exhaust Opening. Vodosnabzheniye i Sanitarnaya Tekhnika 1970, 5, $24-25$.

17. Posokhin, V.N.; Zhivov, A.M. Principles of Local Exhaust Design. In Proceedings of the 5th International Symposium on Ventilation for Contaminant Control, Ottawa, ON, Canada, 14-17 September 2021; Canadian Environment Industry Association: Ottawa, ON, Canada, 1997; Volume 1.

18. He, X.; Lewis, B.V.; Guffey, S.E. Experimental Study on Centerline Velocities of a Rectangular Capture Hood Under Realistic Conditions. J. Occup. Environ. Hyg. 2018, 15, 125-132. [CrossRef] [PubMed]

19. Zhang, J.; Wang, J.; Gao, J.; Xie, M.; Cao, C.; Lv, L.; Zeng, L. Experimental and Numerical Study of The Effect of Perimeter Jet Enhancement on The Capture Velocity of a Rectangular Exhaust Hood. J. Build. Eng. 2020, 33, 101652. [CrossRef]

20. Ansys Inc. Chapter 16 Discrete phase. In Ansys Fluent 17.1, User's Guide; Ansys Inc.: Canonsburg, PA, USA, 2016.

21. Cianferra, M.; Ianniello, S.; Armenio, V. Assessment of Methodologies for The Solution of The Ffowcs Williams and Hawkings Equation Using LES of Incompressible Single-phase Flow Around a Finite-size Square Cylinder. J. Sound Vib. 2019, 453, 1-24. [CrossRef]

22. Lallier-Daniels, D.; Piellard, M.; Coutty, B.; Moreau, S. Aeroacoustic Study of an Axial Engine Cooling Module Using LatticeBoltzmann Simulations and The Ffowcs Williams and Hawkings' Analogy. Eur. J. Mech. B/Fluids 2017, 61, 244-254. [CrossRef]

23. Zhiyin, Y. Large-Eddy Simulation: Past, present and the future. Chin. J. Aeronaut. 2015, 28, 11-24. [CrossRef]

24. Ansys Inc. Chapter 15 Aerodynamically Generated Noise. In Ansys Fluent 17.1, User's Guide; Ansys Inc.: Canonsburg, PA, USA, 2016.

25. Ansys Inc. Chapter 4 Turbulence. In Ansys Fluent 17.1, User's Guide; Ansys Inc.: Canonsburg, PA, USA, 2016.

26. Ansys Inc. Chapter 18 Multiphase Flows. In Ansys Fluent 17.1, User's Guide; Ansys Inc.: Canonsburg, PA, USA, 2016.

27. Jansaengsuk, T.; Kaewbumrung, M.; Busayaporn, W.; Thongsri, J. A Proper Shape of the Trailing Edge Modification to Solve a Housing Damage Problem in a Gas Turbine Power Plant. Processes 2021, 9, 705. [CrossRef]

28. Castle Group. What Is Leq and How Is It Measured. Available online: https:/ /www.castlegroup.co.uk/what-is-leq/ (accessed on 2 September 2021).

29. Brown, P.; Biggs, T.; Crossley, E.; Singh, T. The Accuracy of iPhone Applications to Monitor Environmental Noise Levels. Laryngoscope 2020, 131. [CrossRef]

30. Kardous, C.A.; Shaw, P.B. Evaluation of Smartphone Sound Measurement Applications (apps) Using External Microphones-A Follow-up Study. J. Acoust. Soc. Am. 2016, 140, EL327-EL333. [CrossRef] 